\title{
THE SPIDER GENUS TRACHELAS (ARANEAE, CLUBIONIDAE) IN THE WEST INDIES
}

\author{
By Arthur M. Chickering \\ Museum of Comparative Zoology
}

As I have frequently done in the past, I am again expressing my deep appreciation for the continued help and encouragement in the pursuit of my studies extended to me by the staff of the Museum of Comparative Zoology, Harvard University. The National Science Foundation has aided me very materially by awarding me Grants GB-I8OI and GB-5013. Other foundations, not specifically mentioned here, have also aided me in my studies and collecting trips in Central America and the West Indies. Dr. J. G. Sheals and Mr. D. J. Clark, British Museum (Natural History), have kindly loaned me males and females of Trachelas femoralis Simon from St. Vincent, B. W. I.

\section{The Genus Trachelas L. Koch, 1866}

This genus is known to be widely distributed in many regions of the world. Many species have been described from Central and South America. I have found it quite abundant in Panama where I seem to have collected several new species which are awaiting attention. As far as I have been able to determine, four species have been known from the West Indies. These may be listed as follows: Trachelas bicolor Keyserling, now known from Haiti and Cuba; $T$. borinquensis Gertsch, known only from Puerto Rico, W. I.; T. femoralis Simon, known only from St. Vincent, B. W. I.; T. jamaicensis Gertsch, known only from Jamaica, W. I.

While preparing specimens belonging to this genus, collected in the West Indies in recent years, for deposit in the collections of the Museum of Comparative Zoology I have found several which, apparently, must be regarded as new to science. These may be listed as follows: $T$. bravidus sp. nov.; $T$. cadulus sp. nov.; $T$. domandus sp. nov.; $T$. ecudobus sp. nov.; $T$. mulcetus sp. nov. These are described in the following pages of this paper and all will be deposited in the Museum of Comparative Zoology. Shortly before her death Miss Elizabeth Bryant had, apparently, selected a male from Jamaica, W. I. to be the holotype of a new species but only fragments are now in the vial. I have a female from Jamaica, W. I., St. Catherine Parish, Inswood Estate, Nov. 10, 1963 which may belong with one 
of the described males listed above. Its epigynum is very obscure and some other features seem to leave its status as very uncertain; for these reasons it is not included in this study. Another female from St. Augustine, Trinidad, W. I., April, I964 is omitted from this study for about the same reasons.

\section{Trachelas bicolor Keyserling}

Trachelas bicolor Keyserling, 1887: 440, fig. 15. The female holotype from Haiti, W. I. is in the Museum of Comparative Zoology, examined. Banks, 1903: 340; 1909: 158; Petrunkevitch, 1911: 522; (not T. bicolor Pet., 1930) ; Lutz, 1915: 100 ; Bryant 1933 : 192 ; 1940, 443, figs. 224, 233, 235; 1948: 439; Roewer, 1954: 587; Bonnet, 1959: 4666.

In I940 Miss Bryant described the male of this species from Cuba. In 1948 she reported a male and an immature specirnen from the Dominican Republic.

\section{Trachelas borinquensis Gertsch}

Trachelas borinquensis Gertsch, 1942: 9. The female holotype is from Aibonito, Puerto Rico, June 1,1915 and is in the American Museum of Natural History, New York City.

Trachelas bicolor Petrunkevitch, - 1930: 108, fig. 90.

Apparently, Dr. Gertsch regarded this species as somewhat closely related to $T$. bicolor Keyserling. I have one female of this species from Puerto Rico, Maricao, Monte El Estado, January 9, I964.

\section{Trachelas bravidus sp. nov.}

\section{Figures I-4}

Holotype. The male holotype is from Jamaica, W. I., Portland Parish, Hardwar Gap, November 20, 1957. The name of the species is an arbitrary combination of letters.

Description. Total length, including extended chelicerae, 3.96 $\mathrm{mm}$; total length, excluding extended chelicerae, $3.3 \mathrm{~mm}$. Carapace nearly $1.48 \mathrm{~mm}$ long; I.23 mm wide opposite interval between second and third coxae where it is widest; nearly $0.75 \mathrm{~mm}$ tall in cephalic region where it is tallest; otherwise essentially typical of males of the genus. Eyes: eight in two rows as usual in the genus; viewed from above, anterior row gently procurved and posterior row moderately recurved and occupies nearly the entire width of carapace at that level and is wider than anterior row in ratio of nearly $3: 2$. Ratio of eyes AME : ALE : PME : PLE = nearly IO : II.5 : 9.5 : I I. AME separated from one another by nearly three-fifths of their diameter and separated from ALE by nearly four-fifths of their diameter. PME separated from one another by nearly I.5 times their diameter and separated from PLE by slightly more than twice 

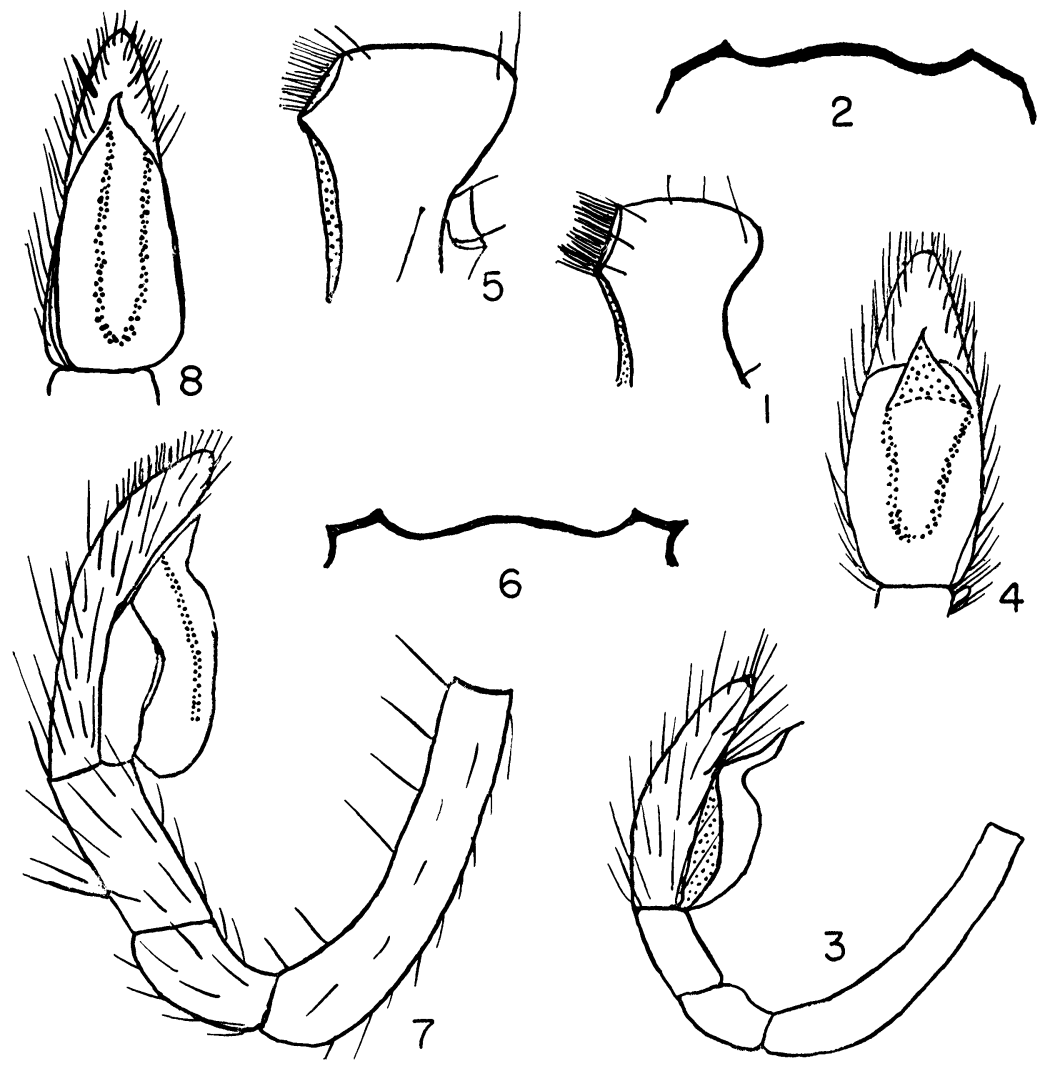

Figures 1-4. Trachelas bravidus sp. nov. Fig. 1. Distal half of left maxilla of holotype from below. Fig. 2. Anterior border of sternum of holotype from below. Fig. 3. Left palp of holotype; prolateral view. Fig. 4. Left palpal tarsus of holotype; ventral view. Figures 5-8. Trachelas cadulus sp. nov. Fig. 5. Distal half of left maxilla from below. Fig. 6 . Anterior border of sternum of holotype from below. Fig. 7. Left palp of holotype; prolateral view. Fig. 8. Left palpal tarsus of holotype; ventral view. 
their diameter. Lateral eyes separated from one another by nearly I.5 times the diameter of ALE. Central ocular quadrangle wider behind than in front in ratio of nearly I7 : 12; only slightly longer than wide in front. Height of clypeus nearly equal to seven-tenths of the diameter of AME. Chelicerae: robust; geniculate near base; surface distinctly granulose; somewhat concave along medial surfaces; keeled along most of the medial margins; lateral margins gently curved; fang regularly curved; fang groove with three teeth along promargin, outer one small and probably with only two along retromargin; with a moderately well developed basal boss and a well developed scopula along promargin of fang groove. Maxillae: quite typical of males of the genus in general; distal, lateral corner well rounded and without any extension such as occurs in T. ecudobus sp. nov. (Fig. I). Lip : nearly three-fifths as long as maxillae; only slightly longer than wide; with basal marginal indentations moderately well developed. Sternum: moderately convex; longer than wide in ratio of nearly $4: 3$ opposite interval between second and third coxae where a narrow extension passes outward for a short distance between second and third coxae; bluntly just opposite bases of fourth coxae which are separated by slightly more than half their width; only moderately rebordered; surface finely granulose; anterior border gently trilobed (Fig. 2). Legs: I 243 in order of length; first leg most robust; spines appear to be lacking; third metatarsus with a fairly well developed brush; with few small cusps on first tibiae, metatarsi and tarsi and still fewer on these segments in second legs. Palp: typical of males of the genus in general; most distinctive features are in the bulb and its embolus; Figures 3 and 4 show the essential features; the tibial apophysis is very short and inconspicuous. Abdomen: quite typical of males of the genus in general; a small, faintly visible, dorsal scutum is present. Color in alcohol: carapace and chelicerae a rich, reddish brown essentially typical of the genus; sternum a light brownish; first femur nearly like sternum; other legs yellowish with some variation; abdomen light yellowish, nearly white with the dorsal scutum weakly chitinized; the four muscle impressions barely visible.

Diagnosis. This species seems to be closely related to $T$. bicolor Keys. but the features of the palp establish it as a new species.

Record. The female is unknown and there are no male paratypes.

Trachelas cadulus sp. nov.

Figures 5-8

Holotype. The male holotype is from Jamaica, W. I., St. Andrew 
Parish, Stony Hill, October 24, 1957. The name of the species is an arbitrary combination of letters.

Description. Total length, including the moderately extended chelicerae and spinnerets, $6.17 \mathrm{~mm}$; excluding the chelicerae and spinnerets, total length is $5.65 \mathrm{~mm}$. Carapace is $2.66 \mathrm{~mm}$ long; $2.04 \mathrm{~mm}$ wide opposite second coxae where it is widest; nearly I.I 7 $\mathrm{mm}$ tall opposite second coxae where it is tallest; gradually raised from posterior border to tallest region; not as abruptly raised as in $T$. bravidus sp. nov.; with a well defined, rather short, median thoracic groove; otherwise typical of males of the genus. Eyes: eight in two rows as usual in the genus. Anterior row gently procurved and posterior row moderately recurved, viewed from above; posterior row occupies nearly the entire width of carapace at that level and is wider than anterior row in ratio of nearly $13:$ Io. Ratio of eyes AME : ALE : PME : PLE = nearly $7: 7: 6.5$ : 6.5 (where eyes are oval to any degree the long axis is always used in measurements). AME separated from one another by slightly more than their radius and separated from ALE by a little more than their diameter. PME separated from one another by nearly twice their diameter and separated from PLE by nearly three times their diameter. Lateral eyes separated from one another by nearly twice the diameter of $A M E$. Clypeus deeply grooved near ventral margin; with height nearly equal to six-sevenths of the diameter of AME. Central ocular quadrangle wider behind than in front in ratio of nearly 13 : 9; wider behind than long in ratio of nearly 26 : 17 . Chelicerae: robust; geniculate near base; granulose; somewhat concave along median surfaces; gently keeled along most of the medial margins; lateral margins gently curved distally from base of moderately developed basal bosses; fang regularly curved; promargin of fang groove with three teeth and retromargin with two teeth; with well developed scopula along promargin of fang groove. Maxillae: quite typical of males of the genus in general; with outer distal corners well rounded without a sharp extension such as is seen in T. ecudobus sp. nov. from Trinidad, W. I.; with a well developed distal medial scopula. Lip: also quite typical of the genus; longer than wide in ratio of nearly $6: 5$; nearly two-thirds as long as maxillae. Sternum: moderately convex; typically rebordered; longer than wide in ratio of nearly $4: 3$; with conspicuous extensions between first and second and second and third coxae; posterior end bluntly rounded opposite bases of fourth coxae which are separated by nearly one-third of their width; surface finely pitted with a short, stiff hair arising from each pit; anterior border trilobed as shown in Figure 6. 
Legs: 1243 in order of length; first leg most robust; no spines observed; cusps fairly numerous on first tibiae, metatarsi but only a few on first tarsi; also only few cusps on second tibiae, metatarsi and tarsi. Palp: essential features shown in Figures 7-8; apparently, the tibial apophysis is reduced to a short, blunt protuberance. Abdomen: in general typical of males in the genus; with a weakly chitinized dorsal scutum covering only the central part of the dorsum and with borders indistinct; the region anterior to the genital groove also weakly chitinized. Color in alcohol: closely similar to that of T. bravidus sp. nov.

Diagnosis. For some time this species was regarded as a variant of $T$. bravidus sp. nov. but close comparison has convinced me that it must be regarded as a new species. The relationships of the eyes; the body size; features of the palp and several other somewhat obscure differences definitely seem to establish it as a separate species.

Records. One male paratype was taken with the holotype but the female remains unknown.

\section{Trachelas domandus sp. nov.}

Figures 9-I3

Holotype. The male holotype is from Jamaica, W. I., Portland Parish, Hardwar Gap, Nov. 20, 1957. The name of the species is an arbitrary combination of letters.

Description. Total length, measured laterally because of curled body, $6.7 \mathrm{~mm}$; total length, measured dorsally as usual and including somewhat extended chelicerae, $6.5 \mathrm{~mm}$. Carapace nearly $3.58 \mathrm{~mm}$ long (somewhat overlapped by abdomen); $2.55 \mathrm{~mm}$ wide opposite second coxae where it is widest; about $1.67 \mathrm{~mm}$ tall in cephalic region where it is tallest; with a well defined, short, median thoracic groove; otherwise essentially typical of males of the genus. Eyes: eight in two rows as usual in the genus. Viewed from above, anterior row gently procurved and posterior row moderately recurved and occupies nearly seven-eighths of width of carapace at that level and is wider than anterior row in ratio of nearly $6: 5$. Ratio of eyes AME : ALE : PME : PLE $=9:$ ıо : $8: 9$. AME separated from one another by slightly more than their radius and separated from ALE by a little more than their diameter. PME separated from one another by nearly twice their diameter and separated from PLE by a little less than 2.5 times their diameter. Lateral eyes separated from one another by nearly I.4 times the diameter of AME. Central ocular quadrangle wider behind than in front in ratio of nearly $3: 2$; wider behind than long in ratio of nearly $5: 4$. 


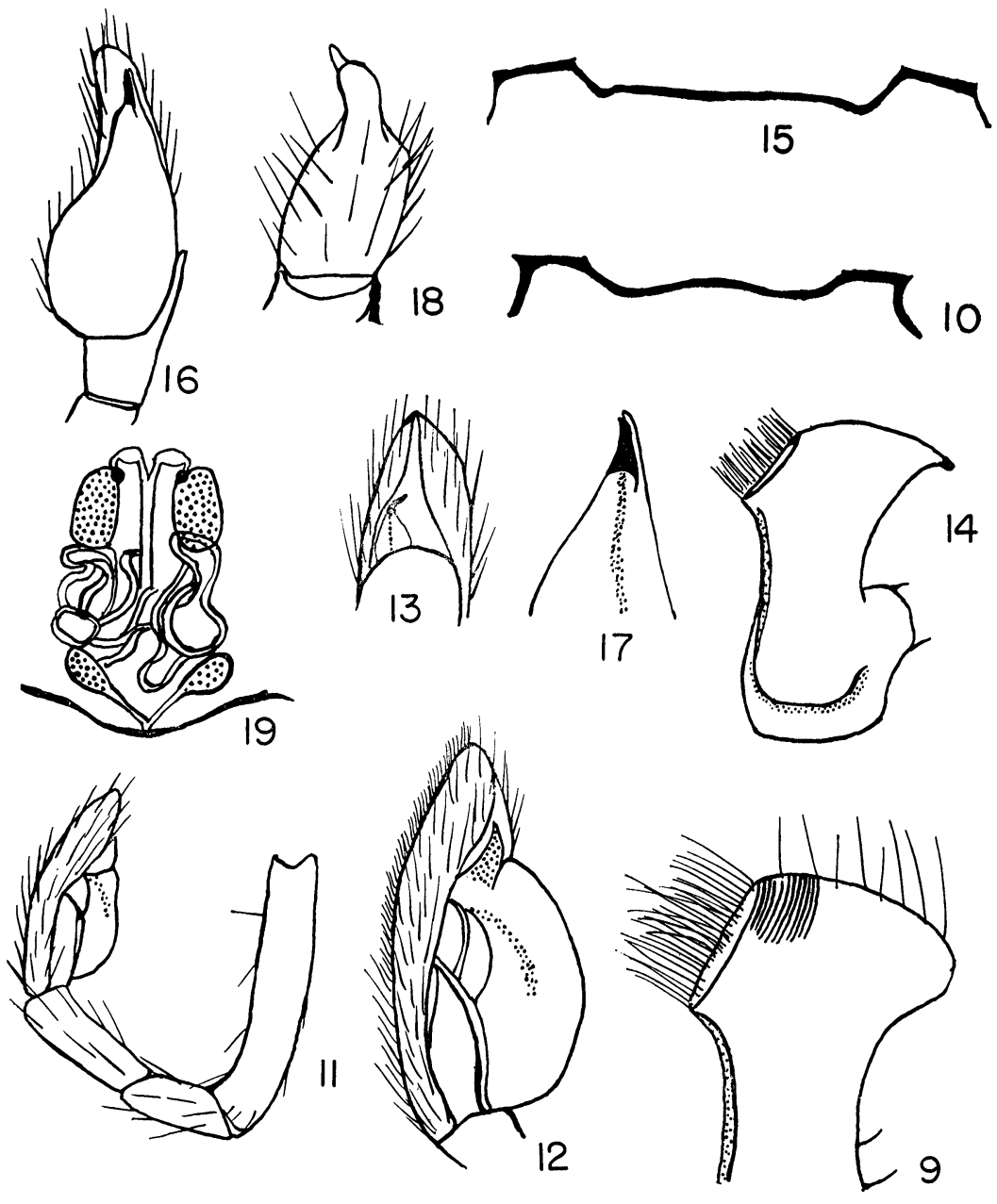

Figures 9-13. Trachelas domandus sp. nov. Fig. 9. Distal half of left maxilla from below. Fig. 10. Anterior border of sternum from below. Fig. 11. Left palp of holotype; prolateral view. Fig. 12. Left palpal tarsus; prolateral view; more enlarged. Fig. 13. Distal end of left palpal tarsus; ventral view. Figs. 14-19. Trachelas ecudobus sp. nov. Fig. 14. Left maxilla of a paratype male; from below. Fig. 15. Anterior border of sternum of holotype from below. Fig. 16. Left palpal tibia and tarsus of holotype; nearly ventral view. Fig. 17. Distal end of left palpal tarsal bulb removed from cymbium of a paratype male. Fig. 18. Left palpal tibia of holotype to show apophysis. Fig. 19. Epigynum of described female paratype from below. 
Height of clypeus nearly equal to diameter of AME. Chelicerae: robust; not definitely geniculate near base as in some other species from this region such as $T$. bravidus sp. nov.; slightly divergent; granulose as usual; lateral margins nearly straight; medial margins without keel and concavity hardly indicated; fang regularly curved; fang groove with three teeeth along promargin and two along retromargin; with a fairly well developed basal boss. Maxillae and Lip: essentially as described for $T$. bravidus sp. nov. and $T$. cadulus sp. nov. with minor differences (Fig. 9). Sternum: moderately convex; with fairly typical margins and lateral extensions; longer than wide in ratio of nearly $39: 30$; widest between second coxae; terminates in a rounded point between bases of fourth coxae which are separated by nearly one-third of their width; anterior border trilobed as shown in Figure 10. Legs: 1243 in order of length; no true spines observed; numerous but not conspicuous cusps occur on tibiae, metatarsi and tarsi of legs one and two. Palp: essential features shown in Figures II-I3; with few slender spines; parts obsclirely distinctive; tibial apophysis very short and barely distinguishable. Abdomen: in general typical of males of the genus; with a faintly outlined dorsal scutum covering the major part of the dorsum; the epigastric region anterior to the genital groove faintly chitinized. Color in alcohol: typical of males of the genus; details regarded as unnecessary for description.

Diagnosis. This is another species which seems to be closely related to $T$. bicolor Keys. The palpal features, the relationships of the eyes, specific shape of the maxillae and a few other specific features establish it as a new species.

Record. The female is unknown and there are no male paratypes.

\section{Trachelas ecudobus sp. nov.}

Figures 14-19

Holotype. The male holotype is from Trinidad, W. I., St. Augustine, April 5, 1964. The name of the species is an arbitrary combination of letters.

Description. Total length, including sonewhat extended chelicerae, $4.18 \mathrm{~mm}$; excluding the chelicerae, total length is $4 \mathrm{~mm}$. Carapace $2 \mathrm{~mm}$ long; $1.34 \mathrm{~mm}$ wide opposite second coxae where it is widest; nearly $0.66 \mathrm{~mm}$ tall in cephalic region where it is tallest; gradually raised from posterior border to highest part a short distance behind PME; otherwise essentially typical of males of the genus. Eyes: eight in two rows as usual in the genus. Viewed from above, anterior row gently procurved, posterior row moderately recurved. Posterior row occupies nearly nine-tenths of width of carapace at 
that level, and is wider than anterior row in ratio of nearly $19:$ I5. Ratio of eyes AME : ALE : PME : PLE = nearly II : I2 : II : IO. AME separated from one another and from ALE by nearly their radius. PME separated from one another by nearly their diameter and from PLE by slightly more than I.5 times their diameter. Laterals separated from one another by nearly 1.5 times the diameter of PLE. Central ocular quadrangle wider behind than in front in ratio of nearly $33: 25$; wider behind than long in ratio of nearly II : IO. Height of clypeus nearly equal to I.2 times the diameter of AME. Chelicerae: robust; somewhat porrect; parallel; somewhat keeled along medial surfaces; only moderately geniculate near bases; fang regularly curved; fang groove with three teeth along each margin. Maxillae: slightly convergent; lateral distal corners extended to a definite pointed termination (Fig. I4, from a paratype); otherwise essentially typical of males of the genus. Lip: nearly three-fifths as long as maxillae; essentially typical of males of the genus. Sternum: moderately convex; longer than wide in ratio of nearly $23: 16$; widest between second coxae; the rounded posterior end reaches just to bases of fourth coxae which are separated by nearly one-half their width; surface granulose; lateral extensions between coxae essentially as usual in the genus; anterior border only bilobed (Fig. I5) ; lateral margins moderately developed. Legs: I $2=43$ in order of length; no true spines observed; trichobothria quite conspicuous on tarsi, especially the fourth; first tibia with a row of about eight ventral cusps and first metatarsus with a ventral row of four or five cusps; second tibia and metatarsus with somewhat fewer ventral cusps (observed on a paratype). Palp: there is a well developed retrolateral, distal, tibial apophysis (Fig. I8); other essential features shown in Figures I6-I7; when the bulb is removed from the cymbium the embolus is seen to be accompanied by a transparent rod or filament closely applied to the embolus and regarded as the conductor; this type of structure has been observed in several species of this genus from Panama where I have collected a rather large number of specimens belonging to this genus. Abdomen: in general quite typical of males of the genus; dorsal scutum quite well outlined and covers the major part of the dorsum; posterior pair of muscle impressions clear but anterior pair very obscure; epigastric region on venter considerably chitinized. Color in alcohol: in general typical of the genus with few minor variations.

Female paratype. Total length, including somewhat extended chelicerae and spinnerets, $4.46 \mathrm{~mm}$; excluding chelicerae and spinnerets, total length is nearly $4.22 \mathrm{~mm}$. Carapace nearly $2.02 \mathrm{~mm}$ 
long; nearly I. $39 \mathrm{~mm}$ wide opposite posterior border of second coxae where it is widest; considerably narrowed opposite palps; nearly $0.95 \mathrm{~mm}$ tall shortly behind PME where it is tallest; surface quite granulose; median thoracic groove as usual. Eyes: in general as in male. Ratio of eyes AME : ALE : PME : PLE = nearly Io : I2.5 : II : IO. AME separated from one another by nearly threefifths of their diameter and separated from ALE by nearly seven-tenths of their diameter. PME separated from one another by nearly $\mathrm{I.2}$ times their diameter and separated from PLE by slightly less than twice their diameter. Lateral eyes separated from one another by nearly I.7 times the diameter of ALE. Central ocular quadrangle wider behind than in front in ratio of nearly $7: 5$; wider behind than long in ratio of nearly $5: 4$. Height of clypeus equal to I.I times the diameter of AME. Chelicerae: somewhat less conspicuously developed than in the male holotype but essentially as in that sex; teeth along fang groove as in the holotype. Maxillae: essentially typical of females of the genus and nearly as in male except that the distal lateral corner is regularly rounded without an extension as in the male. Sternum: essentially as in the holotype; with fourth coxae separated from one another by nearly four-fifths of their width. Legs: 4123 in order of length; no true spines observed but there are numerous long, slender and somewhat conspicuous spiniform bristles; trichobothria have been observed but their number and placement have not been determined; no ventral cusps have been observed. The palpal tarsus bears a small terminal claw and there is a fairly well developed brush of hairs on the dorsal surface of this segment. Abdomen: essentially typical of females of the smaller species in this genus; there is no dorsal scutum but the epigastric scutum is well outlined. The epigynum is obscurely distinctive; the small openings appear to be near the anterior border; the canaliculi are very narrow and intricately inter-coiled and very difficult to trace accurately (Fig. I9); the degree of coiling among the canaliculi varies considerably among the available paratypes.

Diagnosis. This is another species which seems to be closely related to $T$. bicolor. The features of the eyes, the sternum, maxillae, male palp and female epigynum all quite definitely establish it as a new species.

Records. Several dozens of males and females were taken between April I and April 7, 1964 in Trinidad, W. I., St. Augustine on the campus of the University of the West Indies where the species appeared to be abundant. 


\section{Trachelas femoralis Simon}

\section{Figures 20-22}

Trachelas femoralis Simon, 1897: 883. The male and female syntypes from the Island of St. Vincent, B. W. I. are in the British Museum (Natural History), examined. Roewer, 1954: 587; Bonnet, 1959: 4667.

Simon published only a very brief description of both male and female; no figures accompanied the description. I have had two pairs of specimens selected from the syntype series for examination. The following notes have been taken from one of these pairs.

Male. Total length $4.4 \mathrm{~mm}$. Carapace nearly $2.35 \mathrm{~mm}$ long; I.69 $\mathrm{mm}$ wide opposite second coxae where it is widest; nearly I.06 $\mathrm{mm}$ tall shortly behind PME where it is tallest; with continuous gradual descent to posterior border; with a short, moderately well developed median thoracic groove; surface finely pitted; slightly notched opposite first coxae. Eyes: eight in two rows as usual. Viewed from above, anterior row gently procurved and posterior row moderately recurved; viewed from in front, anterior row moderately procurved and posterior row only slightly recurved, almost straight; posterior row wider than anterior row in ratio of nearly io : 7. Ratio of eyes AME : ALE : PME : PLE $=$ nearly I I : 13 : I3 : I2 (outlines somewhat indistinct). Central ocular quadrangle wider behind than in front in ratio of nearly $4: 3$; wider behind than long in nearly the same ratio. AME separated from one another by nearly their radius and separated from ALE by a little more than their radius. PME separated from one another by nearly I.33 times their diameter and separated from PLE by slightly less than their diameter. Lateral eyes separated from one another by nearly twice the diameter of ALE. Height of clypeus nearly equal to the radius of $A M E$. Chelicerae: robust; with well developed basal boss; fang typical of the genus; fang groove with small teeth but exact number not determined because of fragility of the specimen. Maxillae: essentially as shown in Figure 20. Lip: about two thirds as long as maxillae; with two pairs of depressions near base (Fig. 2I). Sternum: with a somewhat distinctive anterior border (Fig. 22) ; longer than wide in ratio of nearly $55: 43$; with the usual conspicuous lateral margins and extensions; posterior end narrowed and nearly squarely truncated just anterior to bases of fourth coxae which are separated by nearly one half of their width. Legs: 1243 in order of length ; first femora very robust; second metatarsus somewhat longer than first; first tibiae, metatarsi and tarsi with a moderate number of the usual ventral cusps; second legs with few cusps. The palp is inconspicuous and its important parts are very difficult 

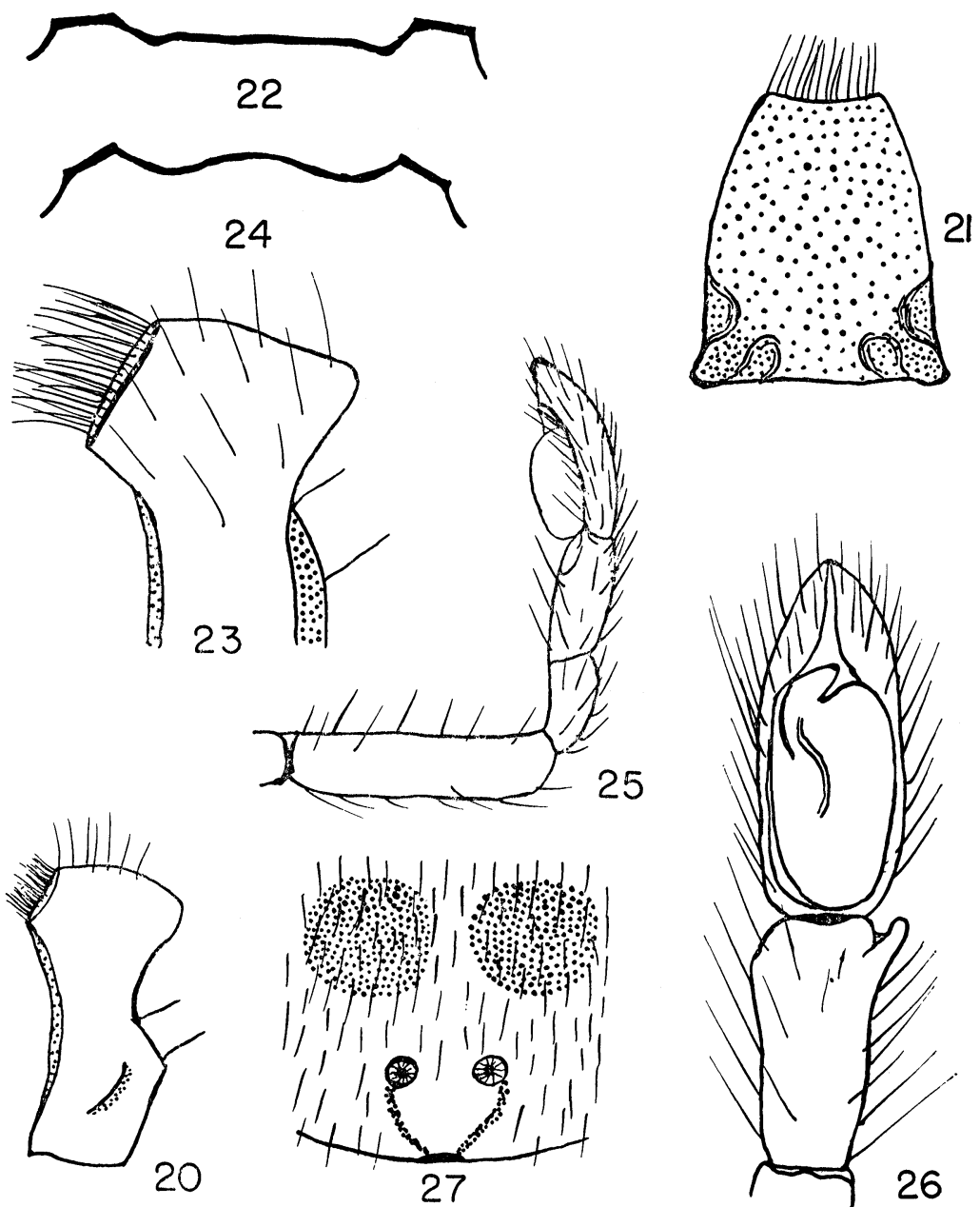

Figures 20-22. Trachelas femoralis Simon. Fig. 20. Left maxilla of male from below. Fig. 21. Lip of male from below. Fig. 22. Anterior border of sternum of male from below. Figures 23-27. Trachelas mulcetus sp. nov. Fig. 23. Left maxilla of holotype from below. Fig. 24. Anterior border of sternum of holotype from below. Fig. 25. Left palp of holotype; retrolateral view. Fig. 26. Left palpal tibia and tarsus of holotype; nearly ventral view; more enlarged. Fig. 27. Epigynum of described female paratype from below. 
to observe; both patella and tibia are short; both together only a little longer than tarsus; no tibial apophysis observed; no figures drawn because of obscurity of parts. Abdomen: essentially typical of males of the genus in general; with a weakly outlined, narrow dorsal scutum. Color in alcohol: quite typical of the smaller species in this genus.

Female. Total length $4.28 \mathrm{~mm}$. Carapace essentially as in male; median thoracic groove barely discernible. Eyes: essentially as in male. Other features very similar to those of male except for the sexual features. Epigynum: very obscure; with small openings close together and placed at some distance anterior to the genital groove; obscurity precludes significant representation in figures. Color in alcohol: very similar to that of male.

I did not collect members of this species during my visit to St. Vincent, B. W. I. in October, 1966 and, apparently, it has not been reported since it was described by Simon.

\section{Trachelas jamaicensis Gertsch}

Trachelas jamaicensis Gertsch, 1942: 9, fig. 28. The female holotype from Jamaica, W. I. is in the American Museum of Natural History, New York City. Roewer, 1954: 587.

One female from Jamaica, W. I., Portland Parish, Blue Mt. Peak, July Io, 1953 (W. G. Lynn) is referred to this species with some uncertainty.

\section{Trachelas mulcetus sp. nov.}

Figures 23-27

Holotype. The male holotype is from Jamaica, W. I., Portland Parish, Blue Mts., Main Range, 5000-7000 ft. elevation, August I 7-I9, I934; collected by Dr. P. J. Darlington, Jr. The name of the species is an arbitrary combination of letters.

Description. Total length, including considerably extended chelicerae, nearly $7.67 \mathrm{~mm}$; total length, excluding the chelicerae, 6.69 $\mathrm{mm}$. Carapace $3.25 \mathrm{~mm}$ long; $2.73 \mathrm{~mm}$ wide opposite second coxae where it is widest; much elevated in cephalic region where it is nearly $1.54 \mathrm{~mm}$ tall; median thoracic groove quite conspicuous with several shallow radiating grooves; somewhat swollen laterally at level of PLE; otherwise quite typical of larger males of the genus. Eyes: eight in two rows as usual in the genus. Viewed from above, anterior row gently procurved and posterior row moderately recurved and occupies slightly more than nine-elevenths of width of carapace at that level and is wider than anterior row in ratio of nearly I6 : I3. 
Ratio of eyes AME : ALE : PME : PLE = nearly $8:$ I I.5 : 8.5 : Io (irregularities in outlines quite noticeable). AME separated from one another by nearly three-fourths of their diameter and separated from ALE by nearly 1.5 times their diameter. Height of clypeus nearly equal to diameter of $A M E$. PME separated from one another by slightly less than twice their diameter and separated from PLE by nearly 2.25 times their diameter. Lateral eyes separated from one another by 1.5 times the diameter of PLE. Central ocular quadrangle wider behind than in front in ratio of nearly I6 : I I; wider behind than long in ratio of $32: 23$. Chelicerae: robust; with well developed basal boss; surface granulose; moderately geniculate near base; lateral margins somewhat swollen distal to boss; without observed keels; fang regularly curved; fang groove with three teeth along promargin and two along retromargin; scopula moderately well developed. Maxillae: typical of males of the genus in general; outer distal corner obtusely rounded (Fig. 23) ; longer than lip in ratio of nearly $20: 13$. Lip: typical of the genus in general; longer than wide at base in ratio of nearly I4 : II. Sternum: moderately convex; longer than wide in ratio of nearly 77 : 60; with lateral extensions as usual in the genus; anterior border trilobed and essentially as represented in Figure 24; surface finely granulose and with many short, stiff hairs; posterior end bluntly rounded just opposite bases of fourth coxae which are separated by nearly half their width. Legs: I 243 in order of length; first legs most robust of the four pairs; no true spines observed; trichobothria observed on several segments; with few spiniform bristles; first leg with several dozen cusps on ventral surfaces of tibia, about half as many on the ventral surface of the metatarsus and only a small number on the tarsus; second legs with a reduced number of cusps on the same segments; third metatarsus with a fairly well developed ventral distal brush. Palp: essential features shown in Figures 25-26; only tibia and tarsus with significant modifications; tibia with a short, distal, retrolateral apophysis; bulb with a terminal, conical embolus tipped at an angle; spiniform bristles somewhat conspicuous on some segments. Abdomen: broad ovoid; with no indication of a dorsal scutum; with very little chitinization in epigastric region. Color in alcohol: cephalothorax, legs and mouth parts nearly typical of the genus; abdomen with a brownish gray dorsum with several very narrow, lighter, irregular, transverse lines near posterior end; venter somewhat lighter, yellowish.

Female paratype. Total length, including extended chelicerae, 
$7.93 \mathrm{~mm}$; total length, excluding the chelicerae, $7 \mathrm{~mm}$. Carapace nearly $3.25 \mathrm{~mm}$ long; $2.6 \mathrm{~mm}$ wide opposite second coxae where it is widest; nearly $1.35 \mathrm{~mm}$ tall in cephalic region a short distance behind PME where it is tallest; in general, quite typical of the larger females in the genus. Eyes: eight in two rows as usual; posterior row wider than anterior row in ratio of nearly $5: 4$ and occupies nearly five-sixths of width of carapace at that level; otherwise essentially as in male. Ratio of eyes AME : ALE : PME : PLE $=$ nearly $7:$ 10 $: 7: 9$. AME separated from one another by slightly less than their diameter and separated from ALE by nearly I.3 times their diameter. PME separated from one another by nearly two diameters and separated from PLE by nearly 2.5 times their diameter. Lateral eyes separated from one another by nearly I.2 times the diameter of ALE. Central ocular quadrangle wider behind than in front in ratio of $7: 5$; about as long as wide in front. Height of clypeus equal to diameter of AME. Chelicerae: robust; more geniculate in front near base than in male holotype; otherwise essentially as in the holotype. Maxillae, lip and sternum all essentially as in holotype with minor variations. Legs: 4I 23 in order of length; otherwise essentially as in the holotype. Palpal tarsal claw very small. Abdomen: essentially as in the male holotype except for the epigynum which is obscurely distinctive; spermathecae and canaliculi very obscure (Fig. 27) ; lack of paratypes prevents more careful examination and clearer representation in drawings. Color in alcohol: cephalothorax, legs and mouth parts essentially typical of females of the genus with minor variations; abdomen essentially as in male with minor differences; the dorsum is more clearly and finely speckled with minute yellowish dots; the transverse, lighter lines across the posterior part of the dorsum are clearer than in the male; the venter is yellowish-brown in general; the epigastric region is quite well chitinized.

Diagnosis. This species appears to be closely related to $T$. jamaicensis Gertsch but the male palpal features, the female epigynum, the relationships of the eyes and other less conspicuous features all seem to establish it as a new species.

Record. Shortly before her death Miss Elizabeth Bryant had, apparently, selected the male and female treated here for description as a new species. They have been awaiting attention in the collections of the Museum of Comparative Zoology since that time. There are no paratypes of either sex available at the present time. 


\section{BANKS, NATHAN}

\section{BIBLIOGRAPHY}

1903. A List of Arachnida from Hayti; with Descriptions of New Species. Proc. Acad. Nat. Sci., Phila. 55: 340-345.

1909. Arachnida of Cuba. Sec. Rept. Centr. Exper. Stat. of Cuba. Pp. 150-174.

\section{Bonnet, Pierre}

1959. Bibliographia Araneorum. Toulouse. 2 (5).

BRYANT, ElizabeTH

1933. New and Little Known Spiders from the United States. Bull. Mus. Comp. Zool., 74(6): 171-193.

1940. Cuban Spiders in the Museum of Comparative Zoology. Bull. Mus. Comp. Zool., 86(7), p. 443.

1948. The Spiders of Hispaniola. Bull. Mus. Comp. Zool, 100(4): p. 439.

GerTsch, W. J.

1942. New American Spiders of the Family Clubionidae. III. Amer. Mus. Novitates, No. 1195: 1-18, 4 pls.

KeYserLing, Graf E. vON

1887. Neue Spinnen aus Amerika. Verh. Zool. Bot. Ges. Wien, 37: 421-490, pl. VI.

\section{LUTZ, FRANK E.}

1915. List of Greater Antillean Spiders, with notes on their Distribution. Ann. N. Y. Acad. Sci., 26: 71-148.

\section{Petrunkevitch, Alexander}

1911. A Synonymic Index-Catalogue of Spiders of North, Central, and South America, etc. Bull. Amer. Mus. Nat. Hist., New York, 29: 1-791.

1930. The Spiders of Porto Rico. Pt. 3. Trans. Conn. Acad. Arts and Sci. 31: 1-191, 168 figs.

ROEWER, C. Fr.

1954. Katalog der Araneae. 2a: 1-923.

SIMON, E.

1897. On the Spiders of the Island of St. Vincent. Pt. III. Proc. Zool. Soc. of London, Nov, 16, 1897: 860-890. 

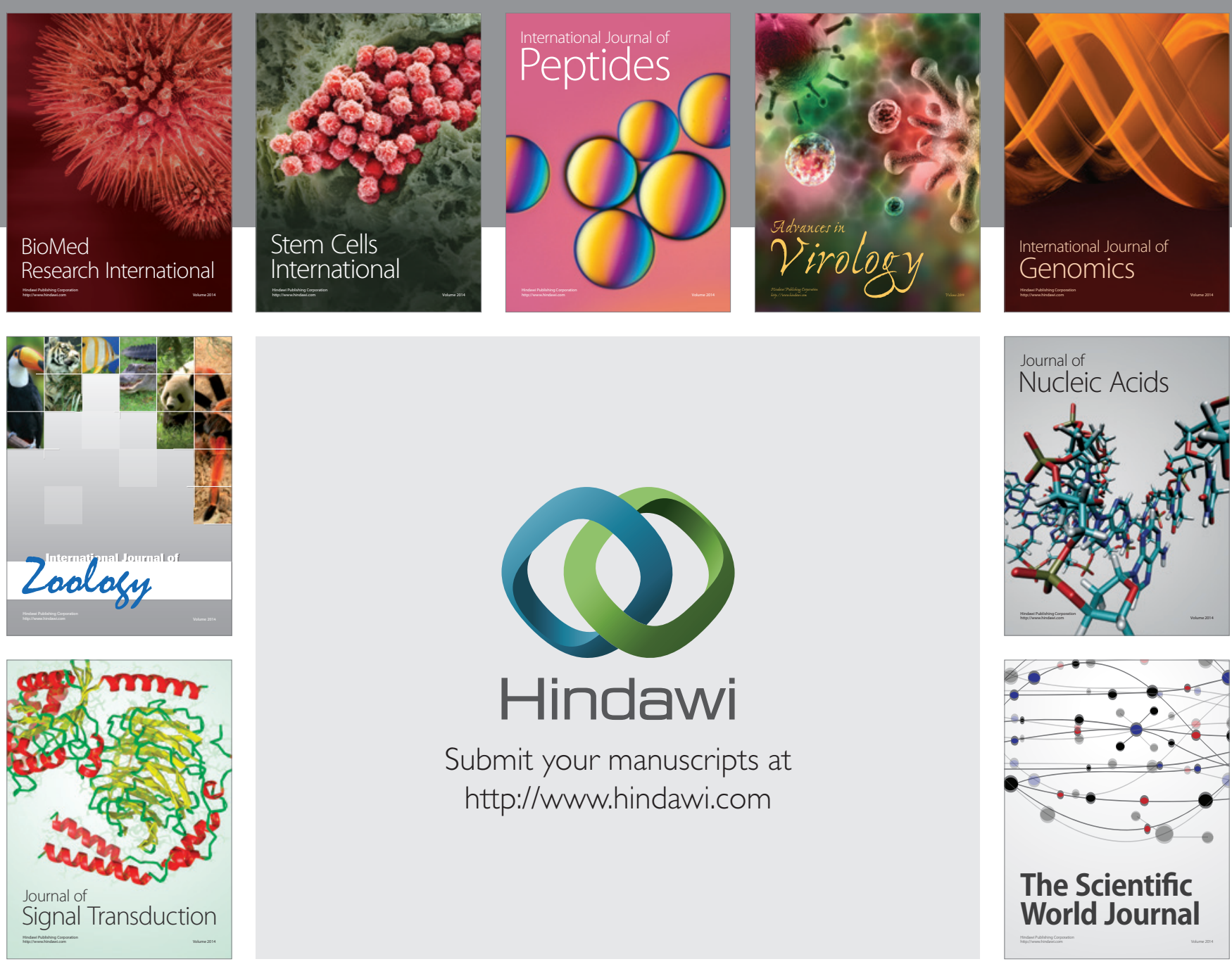

Submit your manuscripts at

http://www.hindawi.com
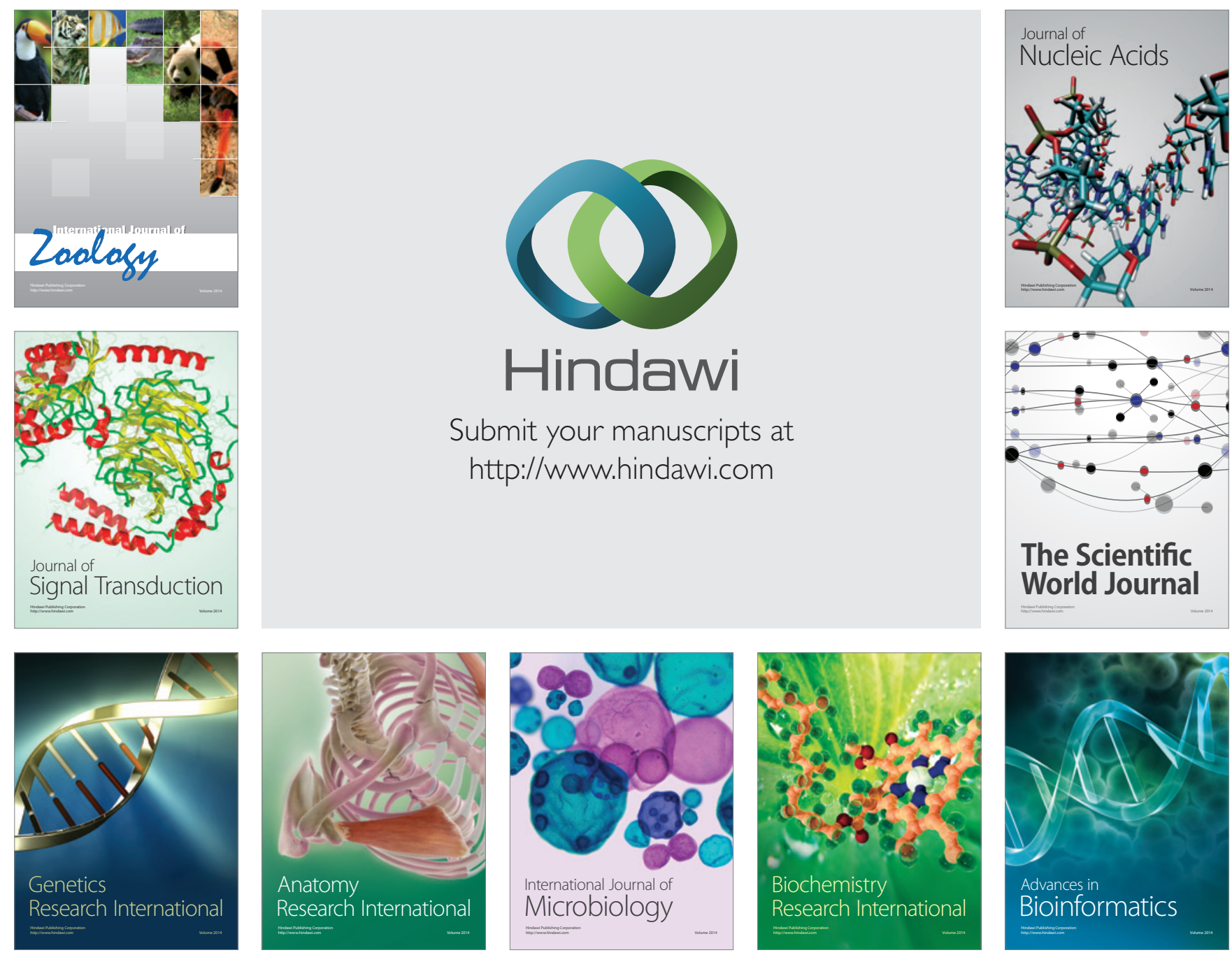

The Scientific World Journal
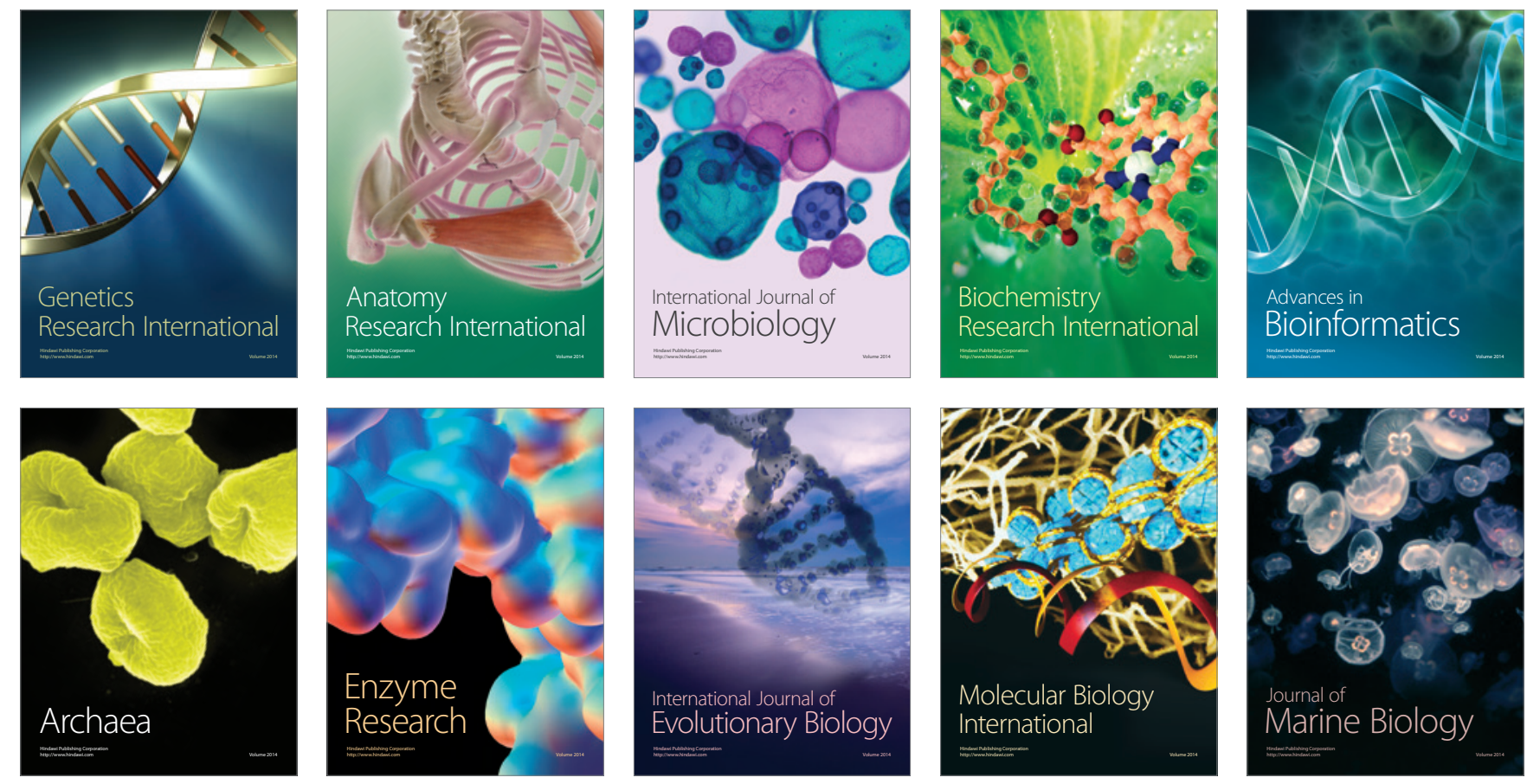